\title{
Experimental investigations of Jominy End Quench test using
} CuO nanofluids

\author{
M Baskaran ${ }^{1}$, KCK Vijayakumar ${ }^{2}$ M. Bharathiraja ${ }^{3}$ \\ ${ }^{1}$ Assistant Professor, Department of Mechatronics Engineering, K.S.Rangasamy College of Technology, \\ Tiruchengode - 637 215, India. \\ baskaranm@ksrct.ac.in \\ ${ }^{2}$ Principal, Department of Mechanical Engineering, Vivekanandha Institute of Engineering \& Technology for \\ Women, Tiruchengode - 637 205, India. \\ vijikck@gmail.com \\ ${ }^{3}$ Assistant Professor (Senior Grade), Department of Automobile Engineering, Kongu Engineering College, \\ Perundurai - 638052, India. \\ bharathi.te@gmail.com
}

\begin{abstract}
Nanofluids are the new class of quenching medium with colloidal suspensions of nanoparticles in base fluids, which improves the heat transfer characteristics. The present work has been focused on the quenching effect of mild steel and EN-8 steel with nanoparticles dispersed quenching medium. The different volume concentrations of nanofluids have been prepared by adding $\mathrm{CuO}$ nanoparticles with the average diameter of less than $50 \mathrm{~nm}$ in distilled water. Three volume concentrations $(0.01 \%, 0.05 \%$ and $0.1 \%)$ of nanofluids have been prepared. EN8 and mild steel rod have machined as per Jominy end quench standard. The materials are heated up to $900^{\circ} \mathrm{C}$ and the heated specimens are Jominy end quenched by using nanofluid. Heat transfer during the cooling has been recorded by interfacing the LabVIEW software, $\mathrm{NI}$-DAQ kit and thermocouple. Then the hardness values are measured at different points on the work piece to examine the change in hardness of the quenched specimens. The result shows that, $0.05 \%$ volume concentration nanofluid exhibits a higher heat transfer rate; consequently the high hardness value has been achieved as compared with other specimens. The same effect has been observed with cooling curve, which was recorded by LabVIEW during the quenching process.
\end{abstract}

\section{Indexing terms/Keywords}

Nano fluid, Hardenability, Heat treatment, Jominy end quench.

\section{Academic Discipline And Sub-Disciplines}

Engineering and Mechanical Engineering

\section{SUBJECT CLASSIFICATION}

Engineering Materials

\section{TYPE (METHOD/APPROACH)}

Experimentalal Investigation

\section{INTRODUCTION}

Applications of steel in engineering industry require a complete knowledge of mechanical properties and manufacturing processes. The common factors to be considered in the automotive industry or modern manufacturing processes are hardness, strength, toughness and low wear resistance. It can be achieved only through modern manufacturing processes. There are different modern manufacturing processes, among this heat treatment is the important one and frequently used. Heat treatment is the process of heating of steel to austenite temperature, then soaking for a specified time period to obtain a homogeneous transformation of austenite structure. Heated specimens are cooled by different methods. Among the various heat treatment methods, quenching is the desirable method to obtain the high hardness value and wear resistance. As per the deep literature survey, it was observed that the Jominy end quench test is the standard method to measure the hardenability of steel.

The purpose of using nanofluids as a quenching medium is to improve the heat transfer rate during the cooling process. In many industrial applications, the conventional heat transfer fluids such as refrigerants, water, engine oil, ethylene glycol are used as a cooling medium. Even though the improvement in energy efficiency is possible from the topology and configuration points of view, but much more focus has been required in the perspective of heat transfer fluid. Despite of considerable research and developments in enhanced heat transfer techniques, cooling capabilities have been constrained because of the poor thermal conductivities of traditional heat transfer fluids. The development of energyefficient heat transfer fluids enhances the thermal conductivity in heat transfer process. One such prominent advancement in the development of heat transfer fluids, is the use of nano-sized (1 - $100 \mathrm{~nm}$ ) solid particles as an additive suspended in the base fluid which will result with enhanced heat transfer rate. 


$$
\begin{aligned}
& \text { ISSN } 2321-807 x \\
& \text { Volume } 12 \mathrm{Number} 10 \\
& \text { Journal of Advances in Chemistry }
\end{aligned}
$$

Nanofluids are heat transfer fluids which consist of nano-sized additive particles with base liquid. The mixture of nanoparticles with water or any other liquid is called as nano heat transfer fluid. The particles are intended to add for improving the thermal properties of the base fluids, which primarily refers to the significant increase in heat transfer dynamics of the cooling process. Base fluids can be water, Ethylene Glycol, Poly Alkaline Glycol (PAG), White metal nano powders ( $\mathrm{Cu}, \mathrm{Au}$, and $\mathrm{Ag}$ ), Oxide-Ceramic particles (Al2O3, CuO, and TiO2), Carbon powders and Carbon nanotubes are added into the base fluid. These fluids have been studied in various fields of thermal engineering [2] showed improved thermal properties of nanofluids. [3] It is found that adding tiny amounts (less than $0.001 \%$ by volume) of alumina nanoparticles to a conventional cooling liquid could significantly increase the Critical Heat Flux (CHF) up to $200 \%$. However, such a large CHF enhancement in nanofluids could not be interpreted using traditional CHF theories, such as hydrodynamic instability models [4]. Because of its potential for remarkable CHF enhancement and scientific interest about its mechanism, boiling heat transfer research of nanofluids has attracted considerable attention, especially for those concerned with CHF. Dissolving nanoparticles in water could be a means to accelerate that transition and, more generally enhance the heat transfer during the quenching process. The common boiling manners of nanofluids have been studied in recent years. The number of investigations showed that the nano fluids can effectively delay Departure from Nucleate Boiling (DNB) with respect to pure fluids [5-6]. It was found that nanoparticle deposition on the boiling surface can occur, which significantly roughens the surface itself [7-11]. Moreover, the deposition of oxide nanoparticles like alumina, copper and titanium appeared to enhance the wettability of the boiling surface significantly [10,12 \& 13]. This effect alters the nucleate boiling heat transfer characteristics of the surface and, specifically the thought to be responsible for the enhancement of the DNB heat flux (Critical Heat Flux - CHF).

On the other hand, as of today only few publications exist concerning the quenching behavior of nanofluids. First, Park et al [14] performed quenching experiments of a high-temperature copper sphere in alumina nanofluids to investigate the effect of the nanoparticles on film boiling heat transfer. The nanoparticle concentration in their experiments was very high (from 5 to $20 \mathrm{Vol} \%$ ), and a sub cooling range from 20 to $80 \mathrm{~K}$ was explored. J.R., Hong et al [15], who carried out quenching experiments of a nickel-plated copper sphere in a pool of water-based nanofluids containing carbon nanotubes (CNT). Based on the assumption that the copper sphere could be thermally lumped, they obtained boiling curves from the temperature-time history of the sphere, using the transient calorimeter technique. Their boiling curves suggested that the CNT nanofluids yield an enhanced CHF, transition boiling heat transfer rate, and minimum heat flux (Leiden frost point) as compared to water. They also found that the wettability of the sphere surface improved due to the surfactant used in the preparation of the CNT nanofluids, and that the CNT deposited on the surface during quenching. J.R., Hong et al [16] investigated the quenching characteristics of water and water-based nanofluids with silicon nanoparticles using a bare platinum wire and a silicon nanoparticle-coated platinum wire. The latter was prepared by boiling a bare platinum wire in the silicon nanofluid. No meaningful differences in the boiling heat transfer characteristics between water and the silicon nanofluid were observed during the experiments with the bare wire. However, a considerably higher heat transfer coefficient was obtained with the nanoparticle-coated wire in the nuclei and the transition boiling regions.

From the above literature, the nanofluid does not experience abnormal heat transfer capability. But it shows little impact in heat transfer, thus the intensity of this work is to study the effect of heat transfer in Jominy end quench test on EN8 steel and mild steel. This paper is aimed to compare the hardness value at different points on different samples quenched by using nanofluids. The heat transfer has been recorded and the corresponding cooling curve to be plotted by using DAQ kit.

\section{METHODOLOGY}

Figure 1 shows the methodology of the Jominy end quench test. It involves the selection of nanoparticle, preparation of nanofluid, preparation of specimens and experimentation.

4456 | P a g e 


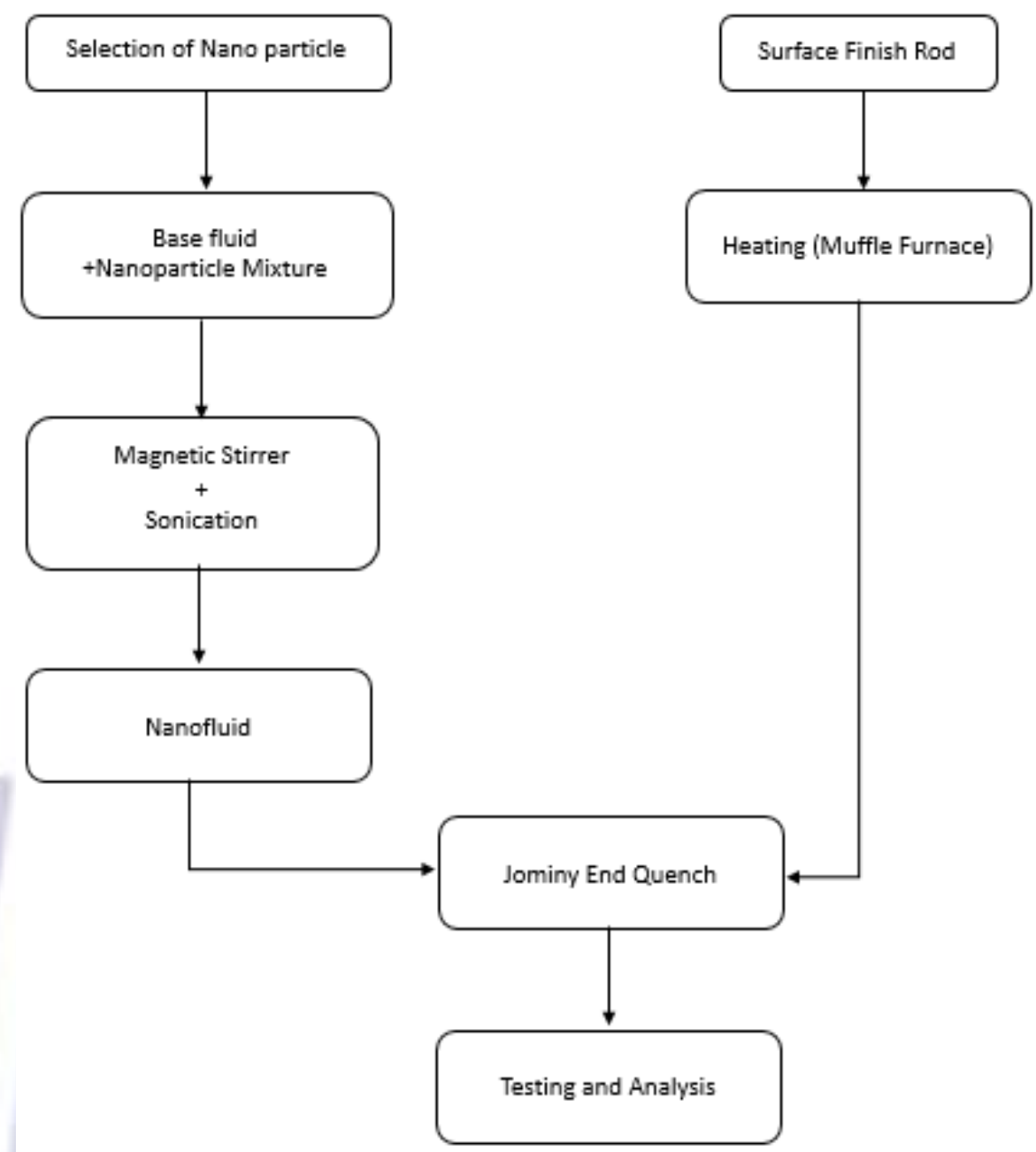

Fig 1: Methodology

\section{EXPERIMENTATION}

\subsection{Preparation of Nanofluid}

A CuO nanoparticle has been selected for preparing the nanofluid, because of their higher thermal conductivity, compared with low cost than Carbon nanotubes, Diamond, Silver nitrate particles. The nanofluids are prepared by dispersing the nanoparticle in de-ionized water by two step method. The CuO nanoparticle was purchased from Sigma Aldrich with the mean size of particles is less than $50 \mathrm{~nm}$. The volume concentration of $\mathrm{CuO}$ particles is listed in Table 1.

Table 1: Volume Concentration of Nanoparticles

\begin{tabular}{|c|c|c|c|c|}
\hline Particle & Appearance & Purity & Particle Size & Seller \\
\hline CuO & Black Powder & 99.99 & $<50 \mathrm{~nm}$ & Sigma Aldrich \\
\hline
\end{tabular}

Table 2 shows the quantity of nanoparticle needed for the preparation of different volumetric concentration of nanofluids. The measured nanoparticles are dispersed in a base fluid (De-ionized water) in mixing container. Then the mixture is stirred around $1000 \mathrm{rpm}$ by using a magnetic stirrer. Prepared nanofluid was visually examined after 12 hours to check the stability of nanofluid.

The nanoparticles were agglomerated in the bottom surface of the container to reduce the agglomeration of particles in nanofluid is sonicated for one hour using ultrasonic sonicator. The agglomeration of particles is considerably reduced by sonication process. Figure 2 shows the stability of nanofluid at different time interval, and finally to investigate the effect of volumetric concentration of nanoparticle on the cooling rate and quenching process of nanofluids. It was experimented that the nanofluid is stable after 24 hours of sonication, but after 48 hours, the particles were slightly settled down in the container. 
Table 2: Required Quantity of Nanoparticles

\begin{tabular}{|c|c|c|c|c|c|c|}
\hline \multicolumn{2}{|l|}{ Density of CUO } & \multicolumn{3}{c|}{$6300 \mathrm{Kg} / \mathrm{m}^{3}$} \\
\hline Density of Liquid (EG/Water) & & & & & \multicolumn{3}{c|}{$1029.6 \mathrm{~kg} / \mathrm{m}^{3}$} \\
& & & & & \multicolumn{3}{c|}{$\begin{array}{c}\text { Required Quantity } \\
\text { of nanoparticles } \\
\text { Vol. concentration }\end{array}$} & (A) & (B) & (C) & (D) & (E) (in gms) \\
\hline 0.01 & 0.0001 & 100 & 0.0971 & 0.00001 & 0.000159 & 0.06119 \\
\hline 0.05 & 0.0005 & 100 & 0.0971 & 0.000049 & 0.000159 & 0.30610 \\
\hline 0.10 & 0.0010 & 100 & 0.0971 & 0.000097 & 0.000159 & 0.61250 \\
\hline
\end{tabular}

\begin{tabular}{|c|l|l|}
\hline A & Volume Concentration in \% \\
\hline B & Quantity of Liquid & $100 / 1029.6$ \\
\hline C & Qty / Density of liquid & $(100 / 1029.6) * 0.0001$ \\
\hline D & $($ Qty / Density of liquid $) \%$ Vol. Concentration & $(1-0.0001) / 2700$ \\
\hline E & $(1 \%$ Vol. Concentration $) /$ Density of $\mathrm{Al}_{2} \mathrm{O}_{3}$ & \\
\hline
\end{tabular}

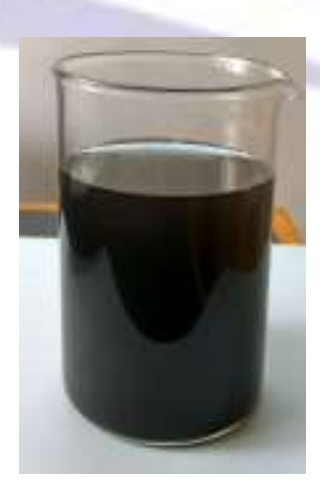

a) After 4 Hours

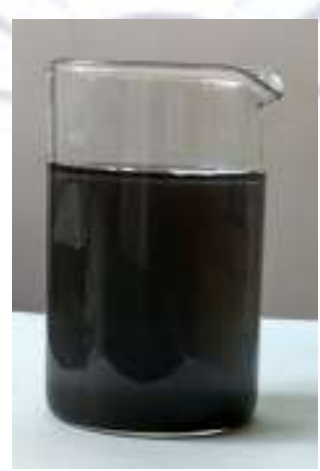

b) After 24 Hours

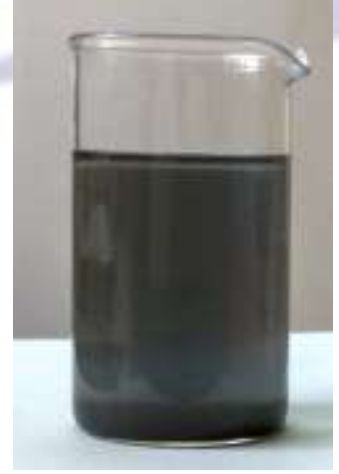

c) After 48 Hours

Fig.2: Stability of Nanofluid at different Time interval 


\subsection{Specimen Preparation}

Two different materials based specimen specifically mild steel and EN-8 steel shafts were purchased with the diameter of $32 \mathrm{~mm}$ and having a length of $500 \mathrm{~mm}$. The shaft material is purchased as a single shaft to avoid changes in property due to changes in material and manufacture. Then the $500 \mathrm{~mm}$ length shaft is machined into 4 pieces of having a $25 \mathrm{~mm}$ diameter and a length of $110 \mathrm{~mm}$. The standard dimensions of the specimen have been referred from previous literatures. Head of the work piece is $28 \mathrm{~mm}$ in diameter and $20 \mathrm{~mm}$ in length for holding the workpiece in the clamp of the shaft. Then the shaft is drilled perpendicular to the axis of the shaft for $12 \mathrm{~mm}$ to place the sensor. Four numbers of samples were prepared with mild steel and EN-8 steel to conduct the experiment. Figure 3 shows the schematic view of the specimen before and after the quench. Table 3 shows the chemical composition of mild steel and EN8 steel.

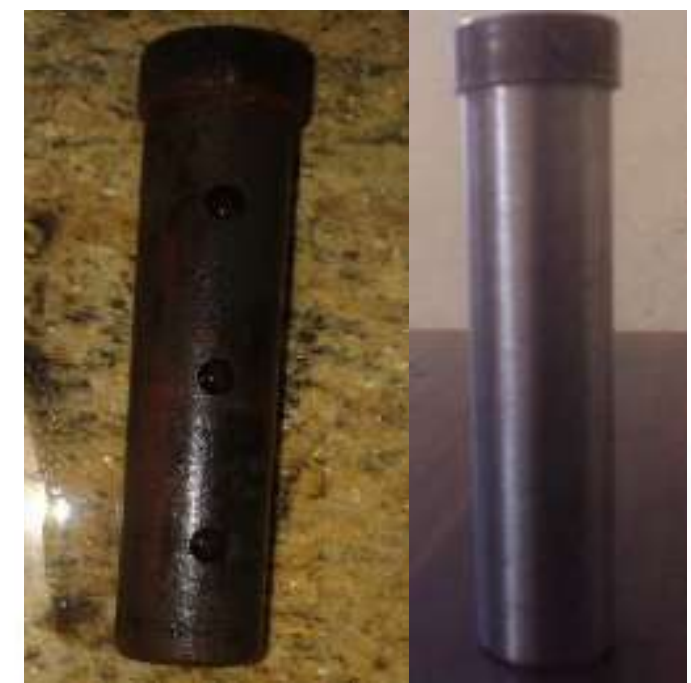

Fig 3: Work piece before and after quenching

\begin{tabular}{|c|c|c|c|c|c|}
\hline Element & Carbon \% & Manganese \% & Silicon \% & Sulphur \% & Phosphorus \% \\
\hline Mild Steel & $0.16-0.18$ & $0.70-0.90$ & $0-0.40$ & $0-0.04$ & $0-0.04$ \\
\hline EN 8 & $0.35-0.45$ & $0.60-1$ & $0.35-0.5$ & $0-0.6$ & $0-0.6$ \\
\hline
\end{tabular}

\subsection{Experimental Setup}

The experimental setup as shown in the Figure 4 is used to conduct the experiment of the Jominy end quench test. This setup consists of a clamp, reservoir, submersible pump, water jet, magnetic stirrer, DAQ and K - type thermocouple. The work piece was held vertically by using clamps and the reservoir was placed at the bottom of the setup, in which the pump was placed to suck the water from the reservoir and pass it to the workpiece through the water jet. Three drills of depth 12 $\mathrm{mm}$ are used to place the thermocouples. The cooling rate of the work piece is measured at the three different places by placing the $\mathrm{K}$ - type thermocouples inside the drills on the work piece, thermocouples will sustain up to the temperature of 1200 oC. The thermocouples are connected with NI-DAQ 9211 temperature DAQ kit. The reservoir is used to store the nanofluid which is used as a quenching medium. A submersible pump is used to pump the nanofluid from the reservoir towards the base of the work piece. Muffle furnace used to heat the work piece to austenite temperature, and placed in the clamp of the setup for quenching process. The entire arrangement of the experiment is conducted by pumping the nanofluid from the reservoir to the base of the work piece, at the same time the cooling curves are recorded by using thermocouple which are connected to the NI-DAQ kit, then the graphs have been generated through LabVIEW software. 


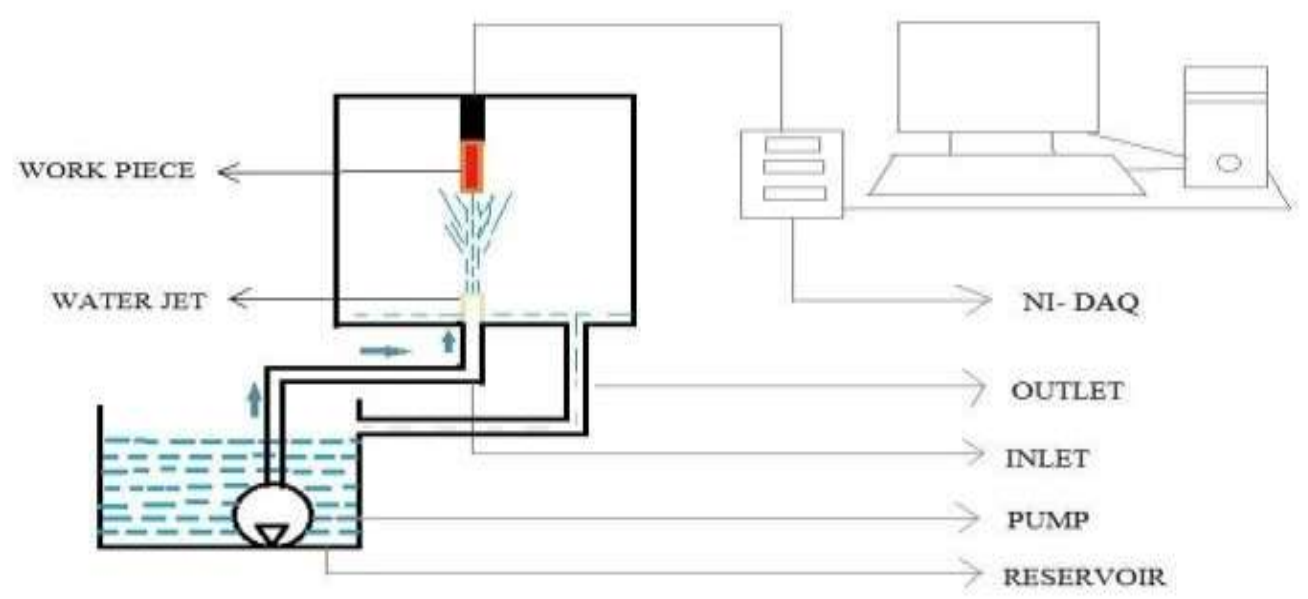

Fig: 4 Experimental setup

\subsection{Experimental Procedure}

The prepared EN-8 steel specimen is cleaned by using an emery sheet to remove the unwanted rust and dust over it. Afterwards washed with water and dried. Then the specimen is heated up to $900^{\circ} \mathrm{C}$ using muffle furnace and the temperature of the specimen is maintained for one hour to complete the austenite formation. At the same time, the nanofluid in the reservoir is stirred by using a magnetic stirrer to avoid the agglomeration of particles. Then the heated specimen is placed in a clamp. Instantly the pump is switched on and it pumps the nanofluid on the workpiece as per Jominy end quench test procedure. The Figure 5 illustrates the cooling of specimen by supplying the nanofluid. During the quenching process, the reduction in temperature is recorded by using DAQ at specified time intervals.

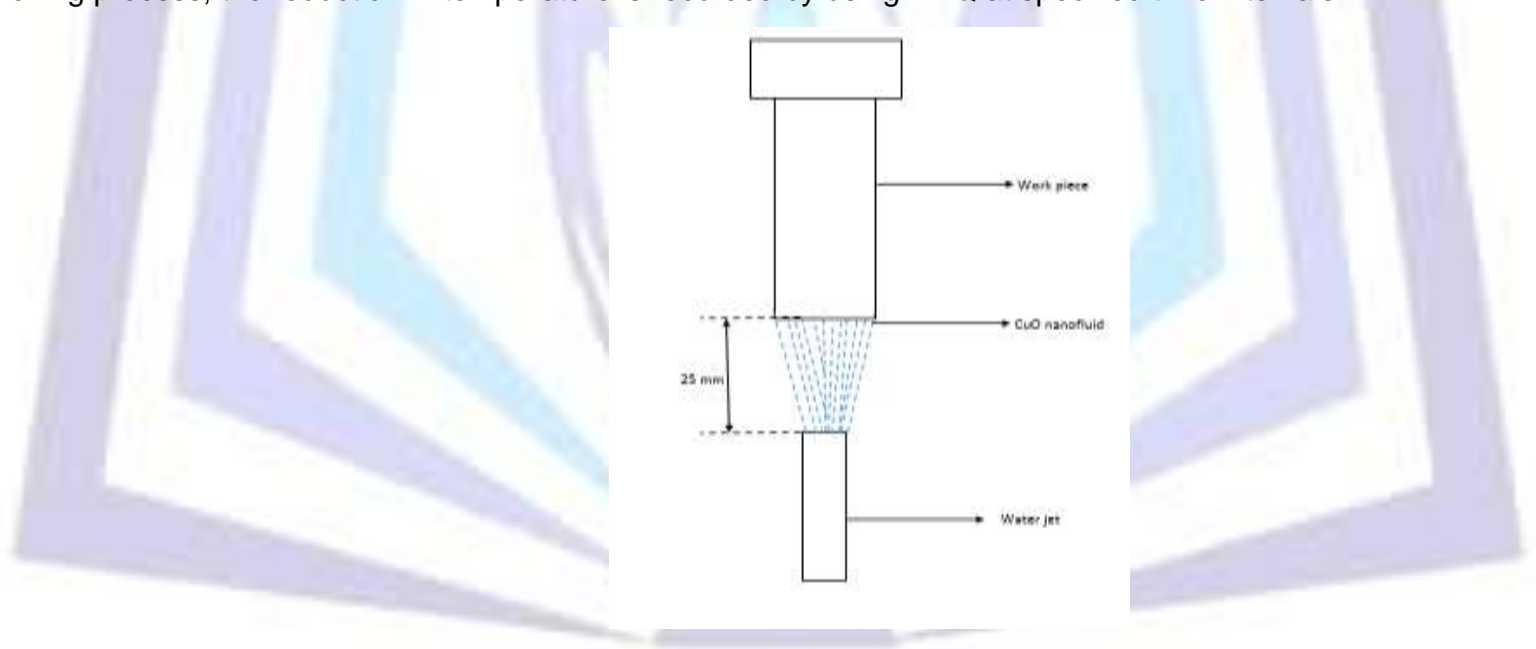

Fig 5: Cooling process

\section{RESULT AND DISCUSSION}

\subsection{Hardenability}

The Rockwell hardness value of the specimen has been recorded and the results were plotted.

\subsubsection{EN-8 Material}

The hardness value of EN-8 steel rod quenched with different concentration of CuO nanofluid mixed with distilled water is shown in the figure. The hardness varies to a great extent in the EN-8 steel when quenched with nanofluid than the distilled water. Three concentrations of nanofluid $0.01 \%, 0.05 \%$ and $0.1 \%$ have been selected for this test, in which the concentration of $0.05 \%$ results with improved hardness than the other two concentrations of nanofluid. At a distance of $10 \mathrm{~mm}$ from the bottom of the work piece the hardness is about $82 \mathrm{HRC}$ (Rockwell ' $\mathrm{C}$ ' scale), and it decreases gradually to the value of $37 \mathrm{HRC}$ at a distance of about $50 \mathrm{~mm}$ from the bottom of the work piece, then the other intermediate hardness values are $65 \mathrm{HRC}, 52 \mathrm{HRC}$ and $40 \mathrm{HRC}$ at a distance of about $20 \mathrm{~mm}, 30 \mathrm{~mm}$, and $40 \mathrm{~mm}$ respectively from the bottom of 
the work piece. In case of the distilled water at a distance of $10 \mathrm{~mm}$ from the bottom the hardness is $58 \mathrm{HRC}$ and $22 \mathrm{HRC}$ at a distance of $50 \mathrm{~mm}$ and the other intermediate values are $44 \mathrm{HRC}, 28 \mathrm{HRC}$ and $25 \mathrm{HRC}$ at a distance of $20 \mathrm{~mm}, 30 \mathrm{~mm}$ $\& 40 \mathrm{~mm}$ respectively from the bottom of the work piece.

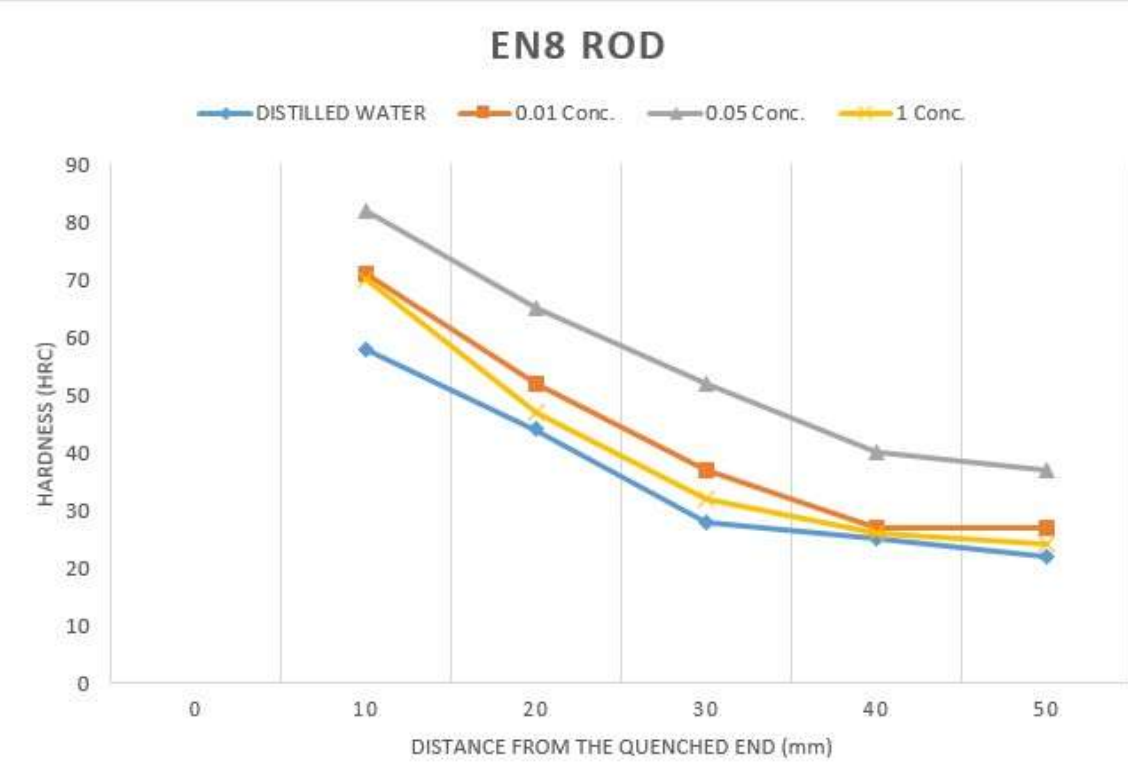

Fig 6: Hardenability of EN-8

For nanofluid concentration of $0.01 \%$ the hardness is about $71 \mathrm{HRC}$ at $10 \mathrm{~mm}, 27 \mathrm{HRC}$ at $50 \mathrm{~mm}, 52 \mathrm{HRC}$ at $20 \mathrm{~mm}, 37$ $\mathrm{HRC}$ at $30 \mathrm{~mm}$ and $27 \mathrm{HRC}$ at $40 \mathrm{~mm}$ respectively from the bottom of the work piece. Then the nanofluid concentration of $1 \%$ has $70 \mathrm{HRC}$ at $10 \mathrm{~mm}$ and $24 \mathrm{HRC}$ at $50 \mathrm{~mm}$ and the other intermediate values are $47 \mathrm{HRC}, 32 \mathrm{HRC}, 26 \mathrm{HRC}$ at a distance of about $20 \mathrm{~mm}, 30 \mathrm{~mm} \& 40 \mathrm{~mm}$ respectively from the bottom of the work piece. Depends upon the heat transfer rate the hardenability of each trial varies with increases in heat transfer rate thereby hardenability increases and vice versa. Thermal conductivity of $\mathrm{CuO}$ nanoparticles is high as compared with distilled water, higher thermal conductivity and heat transfer causes better hardenability. This effect has been proven in this experiment by hardness test result as described above.

\subsubsection{Mild steel}

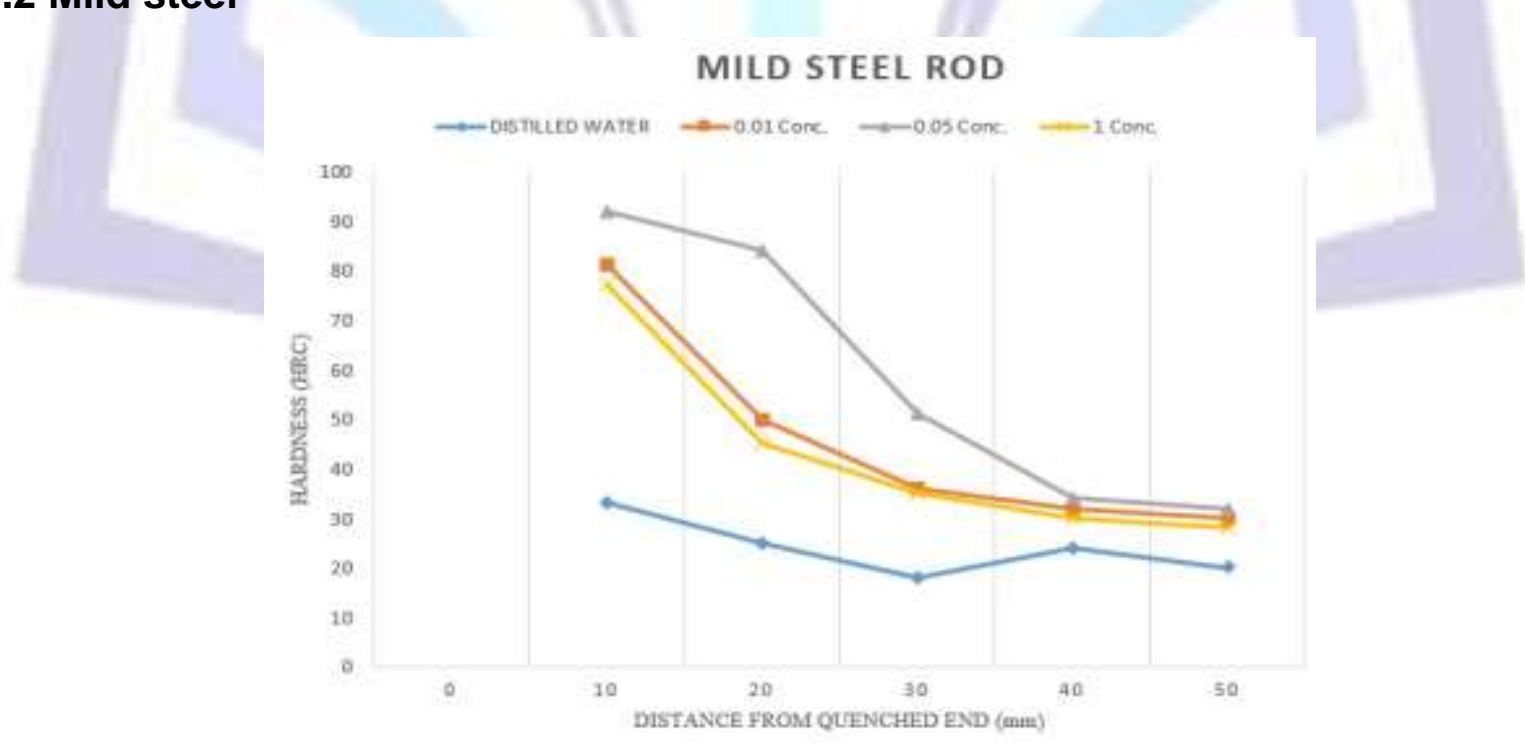

Fig 7: Hardenability of Mild steel

The hardness of mild steel for different concentration of $\mathrm{CuO}$ nanofluid and distilled water is shown in Figure 7. Quenching of mild steel with nanofluid and distilled water is results with an increase in the hardness. Three concentrations of nanofluid $0.01 \%, 0.05 \%$ and $0.1 \%$ are used for this test, in which the concentration of $0.05 \%$ exhibits higher hardness than other two concentrations of nanofluid. At a distance of $10 \mathrm{~mm}$ from the bottom of the work piece the hardness is about 92 
HRC (Rockwell 'C' scale), and it decreases gradually to the value of $32 \mathrm{HRC}$ at a distance of about $50 \mathrm{~mm}$ from the bottom of the work piece. The other intermediate hardness values are $84 \mathrm{HRC}, 51 \mathrm{HRC}$ and $34 \mathrm{HRC}$ at a distance of about $20 \mathrm{~mm}, 30 \mathrm{~mm}$, and $40 \mathrm{~mm}$ respectively from the bottom of the work piece. In case of the distilled water at a distance of $10 \mathrm{~mm}$ from the bottom the hardness is $33 \mathrm{HRC}$ and $20 \mathrm{HRC}$ at a distance of $50 \mathrm{~mm}$ and the other intermediate values are $25 \mathrm{HRC}, 18 \mathrm{HRC}$ and $24 \mathrm{HRC}$ at a distance of $20 \mathrm{~mm}, 30 \mathrm{~mm}, 40 \mathrm{~mm}$ respectively from the bottom of the work piece. For nanofluid concentration of $0.01 \%$ the hardness is about $81 \mathrm{HRC}$ at $10 \mathrm{~mm}, 30 \mathrm{HRC}$ at $50 \mathrm{~mm}, 50 \mathrm{HRC}$ at $20 \mathrm{~mm}, 36 \mathrm{HRC}$ at $30 \mathrm{~mm}$ and $32 \mathrm{HRC}$ at $40 \mathrm{~mm}$ of distance from the bottom of the work piece. Then the nanofluid concentration of $1 \%$ has $77 \mathrm{HRC}$ at $10 \mathrm{~mm}$ and $28 \mathrm{HRC}$ at $50 \mathrm{~mm}$ and the other intermediate values are $45 \mathrm{HRC}, 35 \mathrm{HRC}, 30 \mathrm{HRC}$ at a distance of about $20 \mathrm{~mm}, 30 \mathrm{~mm} \& 40 \mathrm{~mm}$ respectively from the bottom of the work piece. These are all the hardness value attained in the mild steel rod. According to the heat transfer rate, the hardenability of the material varies (i.e) the heat transfer rate is proportional to the hardenability. The thermal conductivity of $\mathrm{CuO}$ particles is higher than the distilled water. Heat transfer rate increases with the increase in thermal conductivity, which causes better hardenability. This effect has been proven in this experiment by the hardness results as described above.

\subsection{Cooling curves of EN-8 and Mild steel rod}

The cooling curve shows that the reduction in temperature with respect to time during the quenching process. The cooling rate of specimen is low, when water is used as a quenching medium. The Figure 9 shows that the nanofluid with the low volume concentration of nanoparticle $(0.01 \%)$ has exhibited more heat transfer rate than the rest of other concentrations. Among the nanofluid concentrations the one with high takes more time to cool than the one with low concentration of the nanoparticle. This was confirmed by using nanofluid as a quenching medium the heat transfer rate increases instead of using water. Nanofluid has better thermal conductivity results with high heat transfer rate than distilled water.

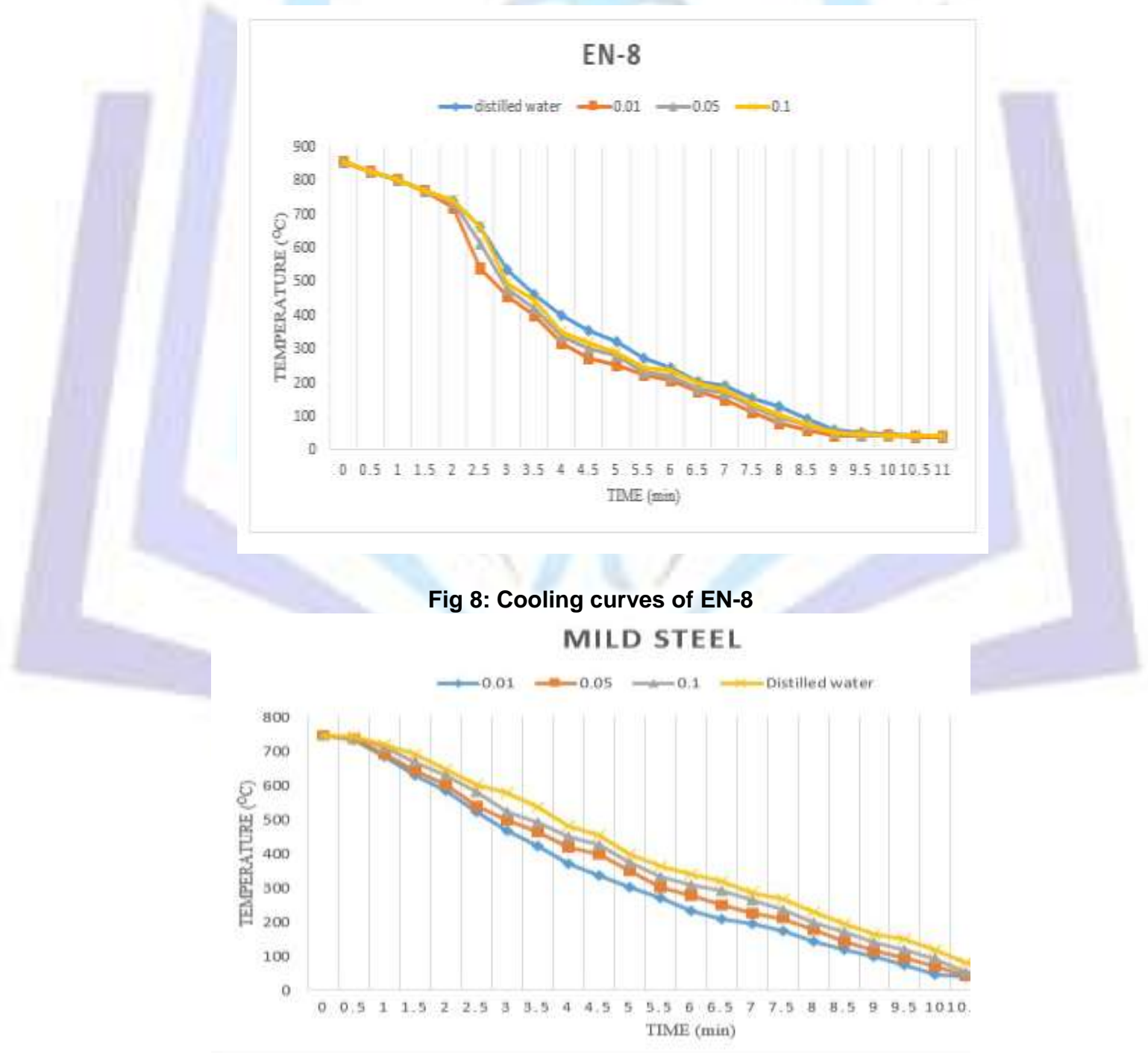

Fig 9: Cooling curves of Mild steel 


\section{CONCLUSION:}

The hardenability investigation has been carried out on EN 8 and Mild steel specimen by using CuO nanofluid. The Jominy end quench hardenability of the material decreases with an increase in the distance of quenching. Though, the heat transfer rate of nanofluid is more when compared with distilled water. Heat transfer rate of quenching medium is mainly influenced by the concentration of the nanoparticle. Quenchant with low concentration of nanoparticle has exhibits better thermal conductivity than the fluid with high concentration. Since the thermal conductivity of the Copper Oxide nanoparticle is high, therefore the nanofluid preparation from the copper oxide has high thermal conductivity. The hardenability graph of the mild steel and the EN-8 material shows that the concentration of the nanofluid with $0.05 \%$ of nanoparticles results in higher hardness than comparing with the others. Cooling curve of the EN-8 and mild steel specimens are experimented separately. The EN-8 curve shows that the cooling rate of distilled water is low as compared with the nanofluids of three different volume concentrations. Out of these three concentrations, the $0.01 \%$ of nanoparticle has a high cooling rate as compared to other concentration. Similar results have been observed from the mild steel specimen.

\section{ACKNOWLEDGMENTS}

The authors are grateful to the management of K.S.Rangasamy College of Technology, Tiruchengode, India for providing the laboratory facilities to carry out the research.

\section{REFERENCES}

1. J. W. Newkirk and D. S. Mackenzie. 2000 "The Jominy end quench for light-weight alloy development".

2. S.U.S. Choi, "Enhancing thermal conductivity of fluids with nanoparticles developments and applications of nonNewtonian flows", FED-vol. 231/MD-vol. 66, 1995, pp. 99-105.

3. You, S.M., Kim, J.H. and Kim, K.H., 2003, "Effect of nanoparticles on critical heat flux of water in pool boiling heat transfer". Appl. Phys. Lett. 83, 3374-3376.

4. Kutateladze, S.S., 1950, "A hydrodynamic model of the critical heat transfer in boiling liquids with free convection", Zhurn, Tekh. Fiz. 20, 1389-1392.

5. Vassallo, R., Kumar, S. and Amico, D., 2004, "Pool boiling heat transfer experiments in silica-water nanofluids", Int. J. Heat Mass Transfer 47, 407-411.

6. Bang, I.C. and Chang, S.H., 2005, "Boiling heat transfer performance and phenomena of Al2O3-water nanofluids from a plain surface in a pool”' Int. J. Heat Mass Transfer 48, 2407-2419.

7. Milanova, D. and Kumar, R., 2005, "Role of ions in pool boiling heat transfer of pure and silica nanofluids", Appl. Phys. Lett. 87, 233107.

8. Kim, H., Kim, J. and Kim, M.H., 2006, "Experimental study on CHF characteristics of water-TiO2 nanofluids", Nucl. Eng. Technol. 38, 61-68.

9. Kim, H., Kim, J. And Kim, M.H., 2006, "Effect of nanoparticles on CHF enhancement in pool boiling of nanofluids", Int. J. Heat Mass Transfer 42, 2003-2013.

10. Kim, S.J. and Bang, I.C., Buongiorno, J., Hu, L.W., 2007, "Surface wettability change during pool boiling of nanofluids and its effect on critical heat flux", Int. J. Heat Mass Transfer 50, 4105-4116.

11. Liu, Z. and Liao, L., 2008, "Sorption and agglutination phenomenon of nanofluids on a plane heating surface during pool boiling", Int. J. Heat Mass Transfer 51, 2593- 2601.

12. Kim, H.D., Kim, J. and Kim, M.H., 2007, "Experimental studies on CHF characteristics of nano-fluids at pool boiling"' Int. J. Multiphase Flow 33, 691-706.

13. Kim, S.J., Bang, I.C., Buongiorno, J. and Hu, L.W., 2006, "Effects of nanoparticle deposition on surface wettability influencing boiling heat transfer in nanofluids", Appl. Phys. Lett. 89, 153107.

14. Park, H.S., Shiferaw, D., Sehgal, B.R., Kim, D.K. and Muhammed, M., 2004, "Film boiling heat transfer on a high temperature sphere in nanofluid", In: Proceedings of 2004 ASME Heat Transfer/Fluids Engineering Summer Conference, Charlotte, NC, pp. 1-8.

15. Xue, H.S., Fan, J.R., Hong, R.H. and Hu, Y.C., 2007, "Characteristic boiling curve of carbon nanotube nanofluid as determined by the transient calorimeter technique", Appl. Phys. Lett. 90, 184107.

16. Choo, Y.J., Chun, S.Y., Park, J.K., Song, C.H. and Bang, I.C., 2008, "Experimental study on boiling heat 
transfer using standard nanofluids", Proceedings of the Seventh International Topical Meeting on Nuclear Reactor Thermal Hydraulics, Operation and Safety, Seoul, Korea.

\section{Author' biography with Photo}

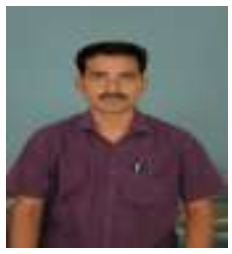

M.Baskaran, Assistant Professor, Department of Mechatronics Engineering at K.S.Rangasamy College of Technology, Tiruchengode, India has acedamic experience of 8 years. He has obtained his Bachelor's Degree in Mechanical Engineering in 2005 from Government college of technology, Salem. He has obtained his Master's Degree in Engineering Design in 2008 from Anna University, Chennai. His research interest is Heat treatment using nano fluids. He has published articles in 2 international journals and 3 national conferences.

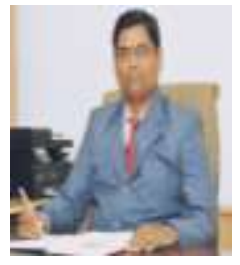

Prof Dr.KCK.Vijayakumar, Principal / Vivekanandha Institute of Engineering and Technology for Women, Tiruchengode, has academic experience of 21 years. He did his B.E. in Mechanical Engineering at Kongu Engineering College in the year 1995. He obtained his M.E. in Engineering Design from Kongu Engineering College in 1998. Later he obtained his Ph.D. from Coimbatore Institute of Technology, Coimbatore in the year 2008. $\mathrm{He}$ has published 16 papers in International journals and 7 papers in National Journals apart from 34 papers in national, international conferences.

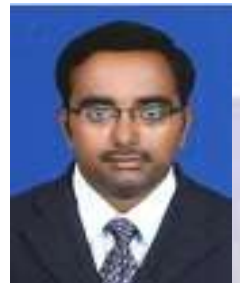

M.Bharathiraja, Assistant Professor (Senior Grade), Department Of Automobile Engineering at Kongu Engineering College, Perundurai has academic experience of 12.5 years.He has obtained his Bachelor's Degree in Automobile Engineering in 2000 from Bharathiyar University, Coimbatore. He has obtained his Master's Degree in Computer Integrated Manufacturing from Anna University, Chennai. He has published 8 papers in international Journals, 3 papers in International conferences and 11 papers in national conferences. 